\title{
Inequality in distribution of burn facilities in Iran
}

\author{
Reza Rezaee ${ }^{1}$, Khalil Alimohammadzadeh*1,2, Seyed Mojtaba Hosseini ${ }^{1}$
}

\section{Abstract}

Background: Inequality in the distribution of medical equipment and facilities has mainly been observed in health centers and, particularly, in governmental hospitals in each country. This study aimed to assess inequality in the distribution of burn facilities in Iran, including burn beds and specialist physicians needed for burn patients in 2017.

Methods: This was a descriptive-analytic study, in which statistical records of the Ministry of Health and Medical Education for 2017 and the Population and Housing Report of 2016 of the Statistical Centre of Iran were used. The main variables studied were number of burn beds and number of general surgeons and plastic surgeons in medical universities in the provinces of Iran. Inequality in the distribution of these variables was evaluated using the Gini coefficient and the Lorenz curve. Excel 2010 software was used for data analysis.

Results: In 55\% of the provinces, the number of beds per capita for 100000 population was lower than the average of Iran (1.26 beds of burn ward), and in $45 \%$ of the provinces, it was higher than the average of Iran in terms of this index. The results showed that burn beds were distributed unevenly in medical universities $(\mathrm{G}=0.42)$. However, the provincial distribution of these beds had a favorable condition $(\mathrm{G}=0.21)$. Also, the numerical value of the Gini coefficient showed the alert status in the distribution of specialist physicians based on the university distribution $(\mathrm{G}=0.51)$.

Conclusion: Although solving the problems related to equality in the distribution of health resources is not an easy task, assessing this issue has a great impact on improving the policymaking procedures and allocating the health system resources. For the first time, this study presented some policies to avoid centralization and prevent some metropolitan cities from turning into cities with limited burn facilities through a comprehensive reviewing of the distribution of the main sources needed by the Iranian burn patients.

Keywords: Inequality in health, Burn facilities, Hospital, Gini coefficient, Lorenz curve

Conflicts of Interest: None declared

Funding: None

\section{*This work has been published under CC BY-NC-SA 1.0 license. \\ Copyright $\subseteq$ Iran University of Medical Sciences}

Cite this article as: Rezaee R, Alimohammadzadeh Kh, Hosseini SM. Inequality in distribution of burn facilities in Iran. Med J Islam Repub Iran. 2019 (4 Nov);33:117. https://doi.org/10.47176/mjiri.33.117

\section{Introduction}

The amount and distribution of health facilities are the most important aspects of health care system that directly affect the quality and quantity of health services and the long-term development of any health system (1). Inequality in distribution of health resources is highly important in

Corresponding author: Dr Khalil Alimohammadzadeh,dr_khali_amz@yahoo.com

1. Department of Healthcare Management, School of Management and Social Sciences, North Tehran Branch, Islamic Azad University, Tehran, Iran

2. Health Economics Policy Research Center, Tehran Medical Sciences Islamic Azad University, Tehran, Iran providing good health services. This disparity in the distribution of medical facilities is observed mainly in health centers and, in particular, in public hospitals in each country (2). Allocating equal health system resources is a prerequisite to achieve equity in health of any community

$\uparrow$ What is "already known" in this topic:

After health sector evolution in 2013, there was an improvement in the quantity and quality of health resources in Iran, but not enough action was taken in resources allocation for burn patients.

\section{$\rightarrow$ What this article adds:}

Although solving the problems related to equality in the distribution of health resources is not easy, assessing this issue has a great impact on improving the policymaking procedures and allocating the health system resources. Inequality assessment and accurate estimation of the resources needed for burn patients can help reduce the direct and indirect costs of health care systems, patients, and households. 
(3). Also, one of the main goals is to implement government interventions in the health services market. For example, government interventions in the distribution of health system resources should lead to higher returns using fewer resources (4). In this regard, the goal of the World Health Organization (WHO) in recent years has been to pursue the policies to ensure equity in health services through rational allocation of resources. The organization announced that it is a fundamental right for any person to benefit from the highest levels of health services regardless of religion, race, economic and social status, and political orientations (5).

The issue of equality and equity in the distribution of health system resources and their impact on the quantity and quality of provided services has challenged health policymakers for long-time and has raised several issues around it. Researchers and policymakers have increasingly considered the equal distribution of health resources, such as staff, beds, doctors, and equipment, as a public health index $(6,7)$. In developing countries, most of the health system resources are unevenly allocated because of the lack of information on health planning and the low level of studies on imbalanced access to the health and medical opportunities (2).

The distribution of health system facilities was examined in different studies. Yue Zhang(6), Wenqi FU (7), Wen Liu (3) and Kaiyuan Zhou (1) assessed the distribution of health system resources. The results of studies on the distribution of health system resources in Iran often show unequal distribution of resources. For example, Hatam's study found that the Gini coefficient for distribution of active beds in Iran was 0.68 , which represented a sharp inequality in the distribution of beds (8). Masoud Asl study obtained the Gini coefficient of 0.46 for distributing beds in different regions of Tehran province, which showed unequal distribution of beds (9). Also, Meshkani (10), Aghamohammadi (11), Hatam (8), and Meshkarpur (12) investigated the distribution of health system resources using the Gini coefficient, Lorenz curve, and other statistical methods.

In recent years, the high incidence of burn injuries has made it an issue of serious concern. On the other hand, managing burn care services with respect to health costs (supply and demand) and high mortality due to burns is an important issue which needs to be addressed. In Iran, the provision of health care services to burn patients has encountered many problems, such as lack of burn beds, inappropriate distribution of burn beds, and high costs of burn treatment both for hospitals and people. The current delivery of burn care services and the services that are limited to specialized hospitals in only some provinces across the country, has been faced with many challenges. Therefore, to better manage the treatment of burn patients in Iran, the facilities needed for burn treatment can be either based on the distribution of burn status among demographic groups or based on more facilities to meet the demands of those patients who are in need of more services. This study aimed to evaluate inequality in burn facilities distribution in Iran, including burn beds and specialist physicians needed for burn patients in 2017 using the Gini coefficient (GC) and Lorenz curve.

\section{Methods}

\section{Study design and data source}

This was an applied descriptive-analytical study. In the statistical analysis, the reports of the Ministry of Health and Medical Education of 2017 and the Population and Housing Report of Iran Statistics Center of 2016 were used. The variables of the study included the number of burn beds per 100000 population and the number of general and restoration surgeons in the medical sciences universities/faculties (MSU/F) in the provinces of Iran. Data were analyzed using Excel 2010.

\section{Statistical analysis}

The GC indicator was used to measure the inequality in the distribution of burn facilities in Iran.

\section{Variables}

The GC indicator was introduced by Anand to measure inequality in the distribution of production factors of health system (13). Therefore, the same indicator was used in this study to assess inequality in the distribution of burn facilities in Iran, including burn beds and specialist physicians required for burn patients in $\mathrm{MSU} / \mathrm{F}$ and in 31 provinces of Iran.

\section{Gini coefficient (GC) and Lorenz curve}

GC shows the dispersion rate in the distribution of a variable. This index is specifically used to assess the inequality in the distribution of income among different socioeconomic groups. On the other hand, this index is the broadest indicator used to measure inequalities in resource distribution. The display of this index is shown by Lorenz curve, which ranges from 0 to +1 . The GC of 0 and +1 represent complete equality and complete inequality in income distribution, respectively (8). The numerical values of the GC have 4 levels for its value: below 0.3 is the best state, between 0.3 and 0.4 normal, beyond 0.4 warning, and 0.6 or more perilous state of the highly unfair (14). Based on the definition, the GC measures the space between the Lorenz curve and the 45-degree line. The horizontal axis represents the aggregate share of the population, in which the population is arranged based on the variable per capita (income, bed, physician, etc.), forming the poorest to the richest groups. The vertical axis also accounts for the share of the same population groups in the variable. The GC is calculated by the following equation:

$$
\mathrm{GC}=1-\sum_{i=0}^{\boldsymbol{k}-\mathbf{1}}\left(\boldsymbol{X}_{\boldsymbol{i}}+\boldsymbol{X}_{\boldsymbol{i}-\mathbf{1}}\right) *\left(\boldsymbol{Y}_{\boldsymbol{i}}-\boldsymbol{Y}_{\boldsymbol{i}-\mathbf{1}}\right)
$$

In the above equation, $\mathrm{Xi}$ and $\mathrm{Xi}+\mathrm{Xi}-1$ show the relative frequency variable for the population variable and the cumulative frequency variable on the horizontal axis, respectively. Also, Yi and Yi-Yi-1 show the cumulative frequency variable for the income variable and the relative frequency variable of income on the vertical axis, respectively (15). 


\section{Results}

One of the important actions in the regional planning with the aims of optimal distribution of medical resources and equipment, reduction of inequalities and attention to balanced and sustainable regional development is the distribution of resources in the form of provincial distribution rather than distribution based on the MSU/F.

This is especially true for burn patients, which prevents centralization of burn centers and facilities from being restricted to metropolitan cities.

Therefore, in this study, in addition to showing inequality in the distribution of facilities needed by burn patients based on the MSU/F, the provincial distribution of these facilities was also evaluated.

\section{Inequality in the burn bed distribution based on the} academic distribution

The distribution of burn beds in the MSU/F of Iran, ranked based on per capita bed for a population of 100 000 people is presented in Table 1 from the lowest to the highest per capita bed in 2017.

Table 1 demonstrates that Shahrood, Zabol and Gonabad have the highest per capita burn bed per 100000 populations, respectively. Also, of $58 \mathrm{MSU} / \mathrm{F}$ of Iran, 32 $\mathrm{MSU} / \mathrm{F}$ were below the national average ( $1.13 \mathrm{beds})$ per capita burn beds per 100000 populations, and $26 \mathrm{MSU} / \mathrm{F}$ was above the national average. Based on the information presented in the table, as well as the Lorenz curve and the Gini coefficient, the Lorenz curve shows the distribution of burn beds in the country / university of medical sciences using Chart 1.

According to Chart 1, the GC of the burn beds distribution in the MSU/F of Iran was obtained to be 0.42 in 2017. Accordingly, the numerical value of this index indicated the warning status in the distribution of burn beds in the country. In other words, contrary to the expectations in 2017, the burn beds were distributed roughly unequally among demographic groups. Also, according to another classification, based on the bed distribution quintuple in the country, the first $20 \%$ of the population groups in the first quintuple, with the worst bed distribution status, included $22 \mathrm{MSU} / \mathrm{F}$ without even a burn bed, while in the last quintuple, $20 \%$ of the population, with the best distribution status of the bed, had 438 burn beds, equal to $47 \%$ of the total burn beds of Iran. For instance, under perfect circumstances, it is expected that $20 \%$ of Iran's burn beds ( 187 beds) be distributed in the first $20 \%$ of the population groups.

\section{Inequality in distributing specialists for burn patients based on academic distribution}

Distribution of burn specialists, including restoration and general surgeons in the MSU/F of Iran, ranked based on physicians per capita for 100000 population, is presented in Table 2, from the lowest to the most doctors per capita in 2017.

Table 2 shows that Gonabad, Shahrood and Jahrom have the highest number of specialists per 100000 population, respectively. Also, of $58 \mathrm{MSU} / \mathrm{F}$ of Iran, $41 \mathrm{MSU} / \mathrm{F}$ were below the national average (0.31specialists) for

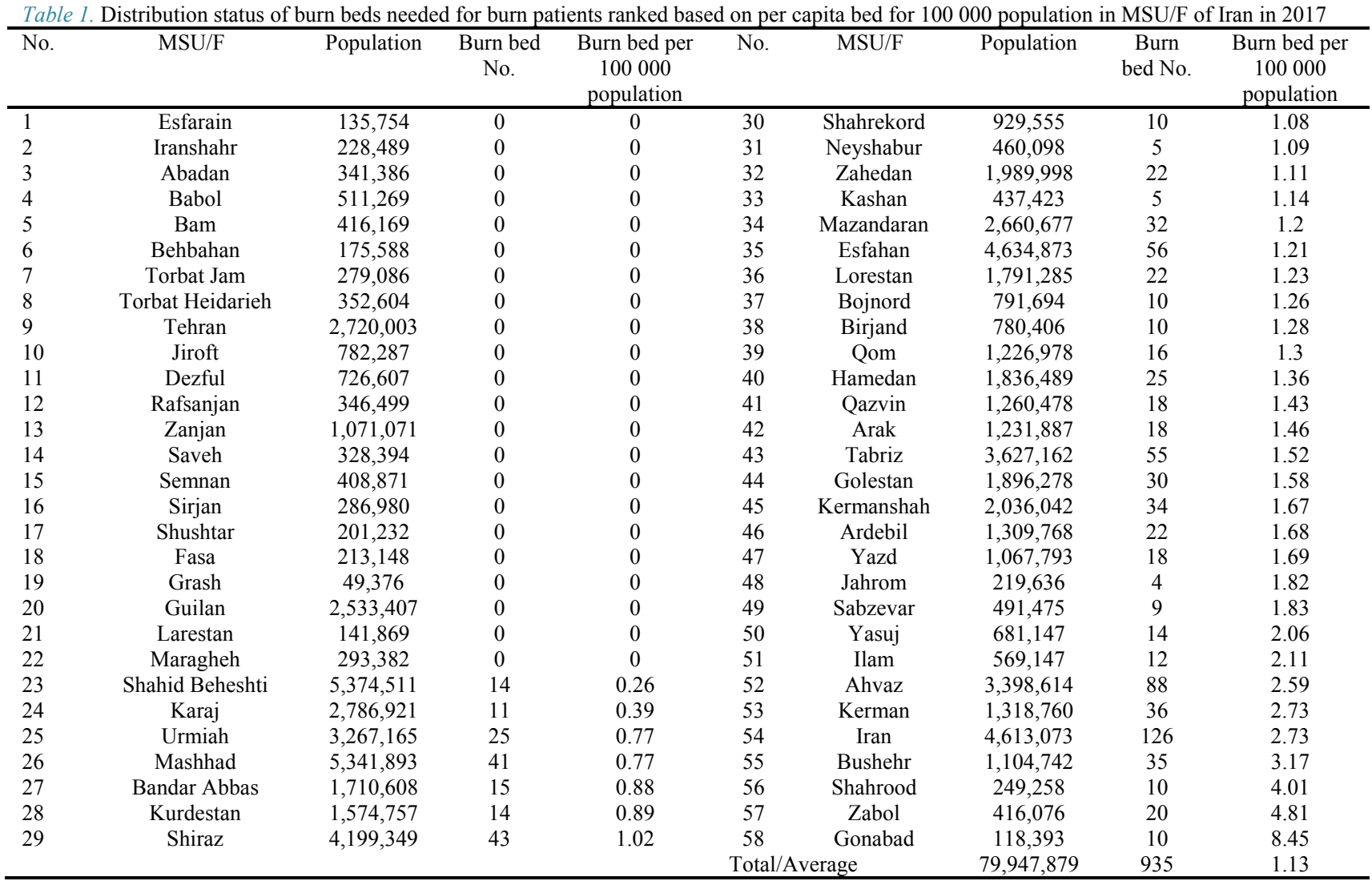




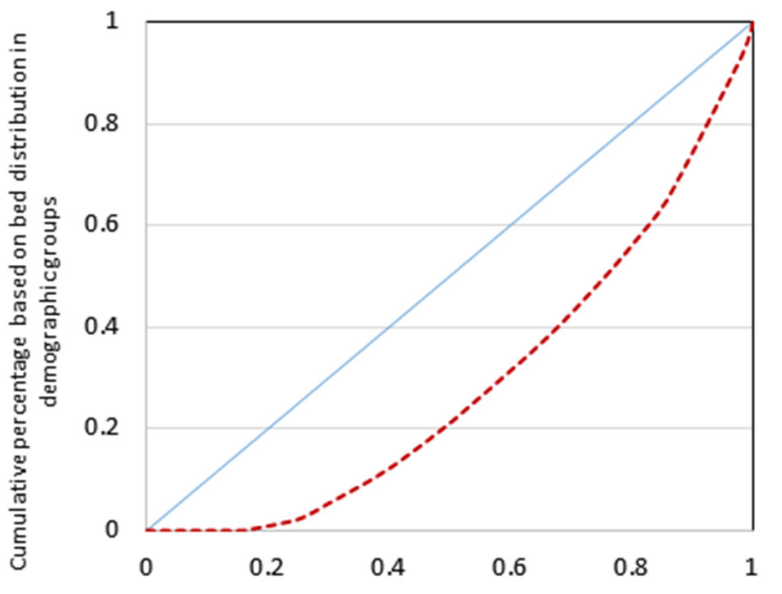

Population cumulative percent, ranked per capita bed per 100,000 population

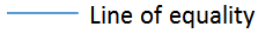

- - - . . Lorenz curve for

specialist distribution per 100,000

Chart 1. Lorenz curve of the burn bed distribution per 100000 population in 2017

Table 2. Distribution status of the specialists needed for burn patients ranked based on doctors per capita for 100000 population in MSU/F of Iran in 2017

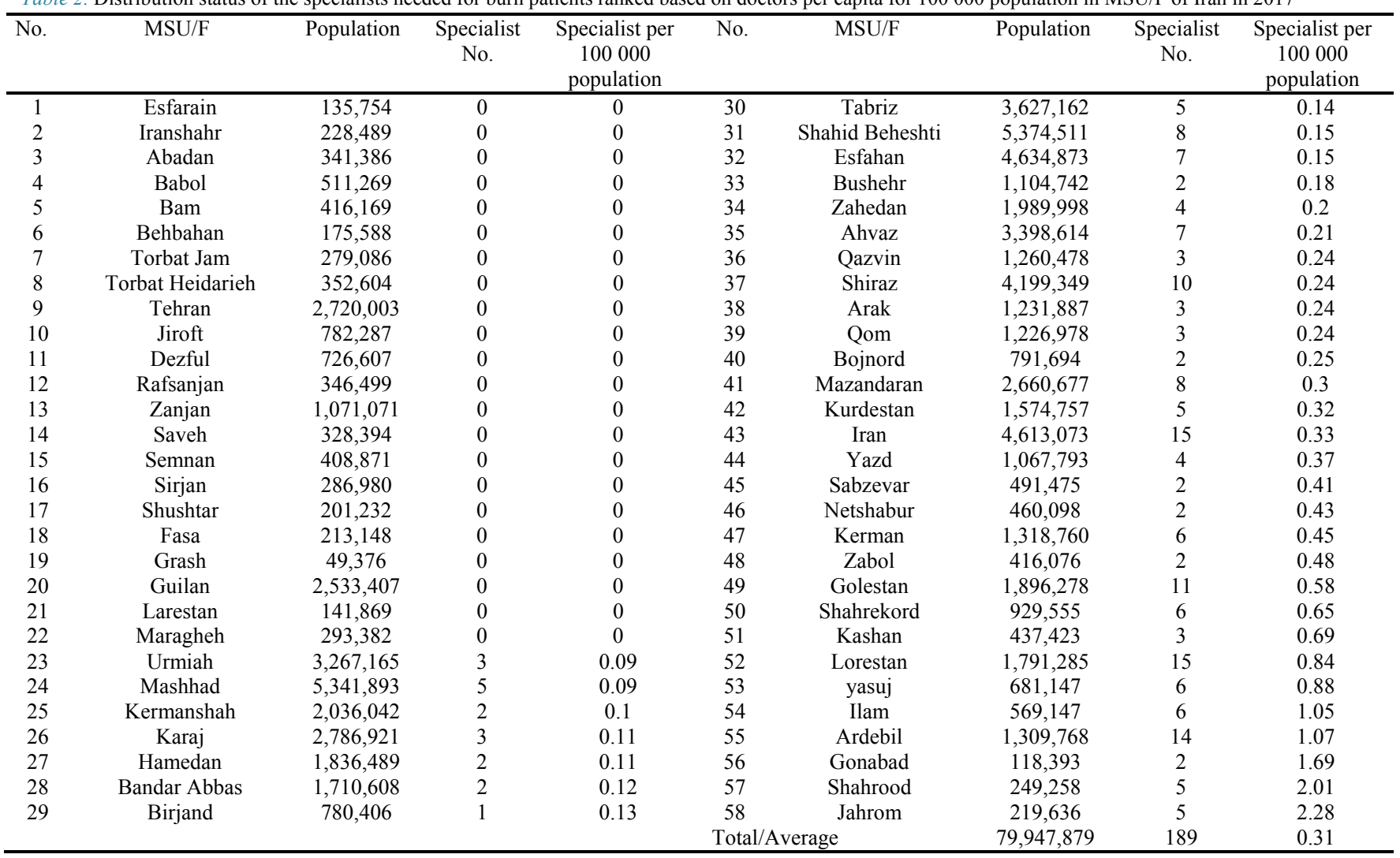

number of specialists per 100000 population, and 17 $\mathrm{MSU} / \mathrm{F}$ were above the national average. According to the data presented in the table, and Lorenz curve and GC, the Lorenz curve of specialists' distribution among MSU/F is presented in Chart 2.

According to Chart 2, the GC of the burn specialists' distribution in the MSU/F of Iran, with a worse condition than the distribution of burn beds, was obtained to be 0.51 in 2017. Accordingly, the numerical value of this index indicated the warning status in the distribution of specialists in the country. In other words, contrary to the expectations in this year, the specialists were distributed unequal- ly among demographic groups. Also, according to another classification based on the specialists' distribution quintuple in the country, the first $20 \%$ of the population groups in the first quintuple, with the worst specialist distribution status included $23 \mathrm{MSU} / \mathrm{F}$ with only 3 specialists. Under perfect circumstances, it is expected that, for example, $20 \%$ of Iran specialists ( 38 physicians) be distributed in the first $20 \%$ of the population groups. In the last quintuple, $20 \%$ of the population with the best distribution status of the specialists had 104 specialists, equal to $55 \%$ of the total specialists of Iran. 


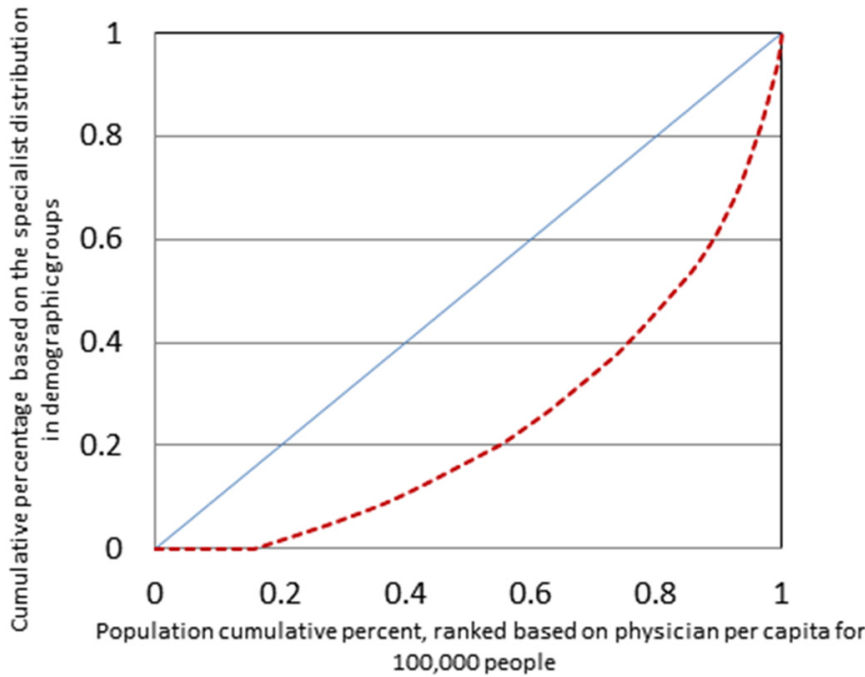

Line of equality

specialist distribution per 100,000

Chart 2. Lorenz curve of the specialist distribution per 100000 population in 2017

Inequality in the burn beds distribution based on the provincial distribution

The distribution of burn beds in the provinces of Iran was evaluated using the Lorenz curve and the GC. Table 3 shows the provinces of Iran ranked per capita bed for 100 000 population, from the lowest to the most per capita in 2017.

Table 3 shows that Kohgiloyeh and Boyer Ahmad, Ilam, and Bushehr have the highest per capita burn beds per 100
000 population, respectively. Also, of the 31 provinces of Iran, 17 were below the national average ( 1.26 beds) specialist per capita per 100000 population and 14 were $45 \%$ above the national average in terms of this index. According to the data presented in the table, Lorenz curve, and GC, the Lorenz curve of burn beds distribution in the provinces of Iran is presented in Chart 3.

According to Chart 3, the GC of the burn beds distribution in the provinces and the population groups was obtained to be 0.21 in 2017 . Accordingly, the numerical val-

\begin{tabular}{|c|c|c|c|c|}
\hline No. & Province & Population & Burn bed No. & Burn bed per 100000 population \\
\hline 1 & Zanjan & $1,057,461$ & - & - \\
\hline 2 & Guilan & $2,530,696$ & - & - \\
\hline 3 & Alborz & $2,712,400$ & 11 & 0.41 \\
\hline 4 & West Azerbaijan & $3,265,219$ & 25 & 0.77 \\
\hline 5 & Hormozgan & $1,776,415$ & 15 & 0.84 \\
\hline 6 & Kurdestan & $1,603,011$ & 14 & 0.87 \\
\hline 7 & Fars & $4,851,274$ & 47 & 0.97 \\
\hline 8 & Mazandaran & $3,283,582$ & 32 & 0.97 \\
\hline 9 & Razavi Khorasan & $6,434,501$ & 65 & 1.01 \\
\hline 10 & Chaharmahal and Bakhtiari & 947,763 & 10 & 1.06 \\
\hline 11 & Tehran & $13,267,637$ & 140 & 1.06 \\
\hline 12 & Kerman & $3,164,718$ & 36 & 1.14 \\
\hline 13 & North Khorasan & 863,092 & 10 & 1.16 \\
\hline 14 & Esfahan & $5,120,850$ & 61 & 1.19 \\
\hline 15 & Qom & $1,292,283$ & 16 & 1.24 \\
\hline 16 & Lorestan & $1,760,649$ & 22 & 1.25 \\
\hline 17 & Markazi & $1,429,475$ & 18 & 1.26 \\
\hline 18 & South Khorasan & 768,898 & 10 & 1.3 \\
\hline 19 & East Khorasan & $3,909,652$ & 55 & 1.41 \\
\hline 20 & Qazvin & $1,273,761$ & 18 & 1.41 \\
\hline 21 & Semnan & 702,360 & 10 & 1.42 \\
\hline 22 & Hamedan & $1,738,234$ & 25 & 1.44 \\
\hline 23 & Sistan and Baluchestan & $2,775,014$ & 42 & 1.51 \\
\hline 24 & Yazd & $1,138,533$ & 18 & 1.58 \\
\hline 25 & Golestan & $1,868,819$ & 30 & 1.61 \\
\hline 26 & Ardebil & $1,270,420$ & 22 & 1.73 \\
\hline 27 & Kermanshah & $1,952,434$ & 34 & 1.74 \\
\hline 28 & Khuzestan & $4,710,509$ & 88 & 1.87 \\
\hline 29 & Kohgiloyeh and Boyer Ahmad & 713,052 & 14 & 1.96 \\
\hline 30 & Ilam & 580,158 & 12 & 2.07 \\
\hline 31 & Bushehr & $1,163,400$ & 35 & 3.01 \\
\hline Total & & $79,926,270$ & 935 & 1.26 \\
\hline
\end{tabular}




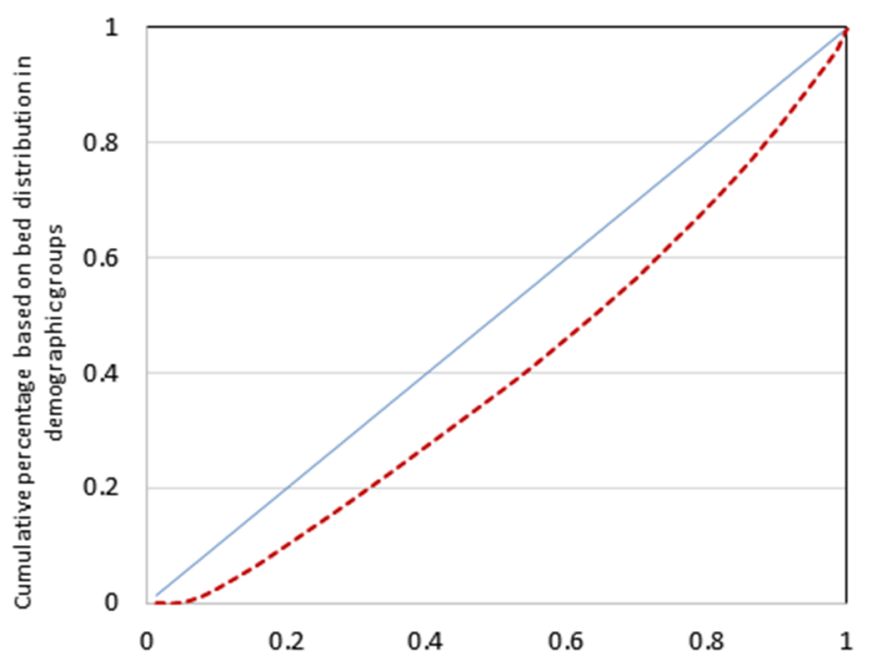

Percentage of population cumulative, ranked per capita per 100,000 population

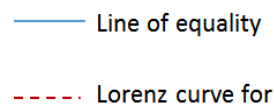

specialist distribution per 100,000

Chart 3. Lorenz curve of the provincial bed distribution per 100000 population in 2017

ue of this index indicated the normal status in the distribution of burn beds in the country. In other words, in this year, the burn beds were nearly equally distributed among the population groups according to provincial distribution.

Also, according to another classification based on the bed's distribution quintuple in the country, the first $20 \%$ of the population groups in the first quintuple, with the worst bed distribution status included 6 provinces with 65 burn beds. Under perfect circumstances, it is expected that, for example, $20 \%$ of Iran burn beds (187 beds) be distributed to the first $20 \%$ of the population groups. In the last quintuple, $20 \%$ of the population, with the best distribution status of the bed, had 295 burn beds, equal to $32 \%$ of the total burn beds of Iran.

Inequality in distributing specialists for burn patients based on provincial distribution

The distribution of general and restorative surgeons in the provinces of Iran was evaluated using the Lorenz curve and the GC. Table 4 demonstrates the provinces of

Table 4. Distribution status of the burn specialist needed for burn patients ranked based on per capita specialist for 100000 population in the provinces of Iran in 2017

\begin{tabular}{|c|c|c|c|c|}
\hline No. & Province & Population & Specialist No. & Specialist per 100000 opulation \\
\hline 1 & Zanjan & $1,057,461$ & - & - \\
\hline 2 & Guilan & $2,530,696$ & - & - \\
\hline 3 & West Azerbaijan & $3,265,219$ & 3 & 0.09 \\
\hline 4 & Kermanshah & $1,952,434$ & 2 & 0.1 \\
\hline 5 & Alborz & $2,712,400$ & 3 & 0.11 \\
\hline 6 & Hormozgan & $1,776,415$ & 2 & 0.11 \\
\hline 7 & Hamedan & $1,738,234$ & 2 & 0.12 \\
\hline 8 & East Azerbaijan & $3,909,652$ & 5 & 0.13 \\
\hline 9 & South Khorasan & 768,898 & 1 & 0.13 \\
\hline 10 & Khuzestan & $4,710,509$ & 7 & 0.15 \\
\hline 11 & Razavi Khorasan & $6,434,501$ & 11 & 0.17 \\
\hline 12 & Bushehr & $1,163,400$ & 2 & 0.17 \\
\hline 13 & Tehran & $13,267,637$ & 23 & 0.17 \\
\hline 14 & Kerman & $3,164,718$ & 6 & 0.19 \\
\hline 15 & Esfahan & $5,120,850$ & 10 & 0.2 \\
\hline 16 & Markazi & $1,429,475$ & 3 & 0.21 \\
\hline 17 & Sistan and Baluchestan & $2,775,014$ & 6 & 0.22 \\
\hline 18 & North Khorasan & 863,092 & 2 & 0.23 \\
\hline 19 & Qom & $1,292,283$ & 3 & 0.23 \\
\hline 20 & Qazvin & $1,273,761$ & 3 & 0.24 \\
\hline 21 & Mazandaran & $3,283,582$ & 8 & 0.24 \\
\hline 22 & Fars & $4,851,274$ & 15 & 0.31 \\
\hline 23 & Kurdestan & $1,603,011$ & 5 & 0.31 \\
\hline 24 & Yazd & $1,138,533$ & 4 & 0.35 \\
\hline 25 & Golestan & $1,868,819$ & 11 & 0.59 \\
\hline 26 & Chaharmahal and Bakhtiari & 947,763 & 6 & 0.63 \\
\hline 27 & Semnan & 702,360 & 5 & 0.71 \\
\hline 28 & Kohgiloyeh and Boyer Ahmad & 713,052 & 6 & 0.84 \\
\hline 29 & Lorestan & $1,760,649$ & 15 & 0.85 \\
\hline 30 & Ilam & 580,158 & 6 & 1.03 \\
\hline 31 & Ardebil & $1,270,420$ & 14 & 1.1 \\
\hline \multicolumn{2}{|c|}{ Total/Average } & $79,926,270$ & 189 & 0.32 \\
\hline
\end{tabular}




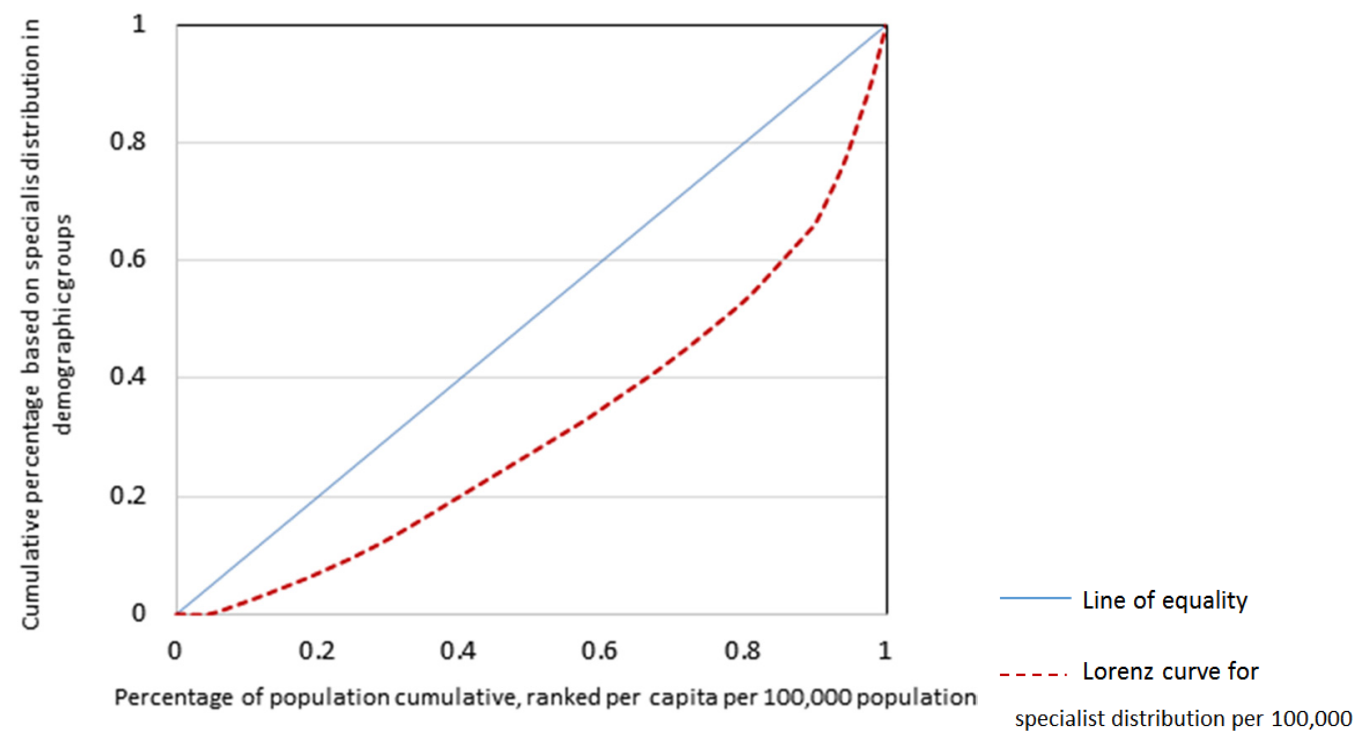

Chart 4. Lorenz curve of the provincial specialist distribution per 100,000 populations in 2017

Iran ranked per capita specialist for 100000 population, from the lowest to the most per capita in 2017.

Table 4 shows that Lorestan, Ilam, and Ardebil have the highest per capita specialists per 100000 population, respectively. Also, of the 31 provinces of Iran, 23 were below the national average in specialists per capita per 100 000 population ( 32.0 specialists) and 8 provinces were $26 \%$ above the national average in terms of this index. According to the data presented in the table, Lorenz curve, and GC, the Lorenz curve of the specialists' distribution in the provinces of Iran in demonstrated in Chart 4.

According to Chart 4, the GC of the specialists' distribution in the provinces and the population groups was obtained to be 0.37 in 2017 . Accordingly, the numerical value of this index indicated the average status in the distribution of the specialists in Iran. In other words, in this year, the specialists were nearly unequally distributed among the population groups according to provincial distribution.

Also, according to another classification based on the specialists' distribution quintuple in Iran, the first $20 \%$ of the population groups in the first quintuple with the worst physician distribution status included 7 provinces with 12 doctors. In the presence of complete equality, it is expected that, for example, $20 \%$ of the c specialists (38 doctors) be distributed in the first $20 \%$ of the population groups. Also, in the last quintuple, $20 \%$ of the population with the best distribution status of the physician had 95 specialists, which is equal to $50 \%$ of the total country doctors.

\section{Discussion}

The current status of Iran's health care system (late fifties) indicates that the distribution of medical personnel in the country was highly heterogeneous, with $69 \%$ of the physicians in Tehran and 18\% in Tabriz, Mashhad, Ahvaz, Shiraz, and Isfahan, and $13 \%$ in the rest of Iran (16). The equal and balanced distribution of the resources, especial- ly expert human resources and hospital beds in the health sector, is one of the factors that promotes health indicators and, consequently, increases social equity and equality. In their research, Ghazi Mir Saeid et al stated that although the production of health specialists has been increasing in the recent years, their proper distribution in hospitals seems to be problematic (17). This issue is of great importance for the burn facilities, which had a high prevalence in recent years. Therefore, the present study considered the distribution of beds and manpower related to health.

The results of this study showed unfair distribution of burn beds in universities of medical sciences $(\mathrm{GC}=0.42)$. However, the distribution of these beds in provinces $(\mathrm{GC}=0.21)$ was more favorable. In a study by De Bruin et al (2010) on the distribution of CCU beds in 24 Dutch academic hospitals during 2004-2006, the GC was reported to be 0.65 and 0.5 for these years, respectively. Their study clearly expressed the unequal distribution of the beds in the studied hospitals (18). Tooia Horo et al, in their study with the aim of investigating the process of geographical disparities in resource allocation in the United States, pointed to an equity downward trend in the distribution of doctors compared to the hospital beds over a 30-year period (19). Also, Olsen et al (2005) in their study titled, "Measuring inequality in the distribution of health workforce in Tanzania", found that the distribution of expertise in Tanzania was unbalanced and unequal (20). Horev et al (2004), in their study, used the GC to calculate disparities in the distribution of doctors and hospital beds. The results of their study indicated that the distribution of doctors was somewhat unfair, but the distribution of hospital beds seemed to be fair (19). Matsumotoa et al (2010) who calculated GC concluded that the distribution of physicians working in Japanese hospitals was not in a good condition during 1996 to 2006 (21).

The results of the present study and other studies showed that considering the number of beds and manpower as the basis of equity, the health condition of the stud- 
ied areas is faced with a lot of inequities. Although solving problems related to equity in the distribution of health resources and in particular its measurement does not seem to be uncomplicated, this issue has a major impact on the policymaking and allocation of resources in the health system (22). In this regard, WHO has also emphasized on the importance of measuring equity in the distribution of resources. Access to health services is a fundamental human right; however, inequality in the geographical distribution of health resources makes access to these services difficult (23). These problems are more common in developing countries due to limitations of the recording, collecting, storing, and analyzing information systems for planning in the health sector. Hence, the level of geographical equity and equity in the distribution of health resources as a public health index should be increasingly focused (24).

One of the main reasons of this issue is the low number of specialists in the related provinces due to limited number of acceptances in the field of burn and restoration at the country level. Some countries are trying to provide direct financial incentives for the health workforce to make them more willing to work in rural areas (25), including scholarships (26), providing direct financial incentives for people who chose deprived and rural areas (27), and granting loans to physicians working in rural areas (28).

\section{Conclusion}

Given that hospital beds are the most important criterion for calculating other required conditions, including physicians, nurses and equipment, the equality in the distribution of burn beds can implicitly equate the distribution of other service delivery factors. Thus, policymakers are expected to apply frequent monitoring in this regard and examine the distribution of hospital beds. It is suggested that health policymakers and other key decision makers at the Ministry of Health and Medical Education financially support the graduates of medical specialties, set regulations, and provide educational and professional support.

\section{Acknowledgements}

This study was prepared with the assistance of the Ministry of Health's Office of Budget and Credits, and its preliminary results were presented in a doctoral thesis titled, "Designing a comprehensive management system for treating burn patients in Islamic Republic of Iran".

\section{Conflict of Interests}

The authors declare that they have no competing interests.

\section{References}

1. Zhou K, Zhang X, Ding Y, Wang D, Lu Z, Yu M. Inequality trends of health workforce in different stages of medical system reform (19852011) in China. Hum Resour Health. 2015;13(1):94.

2. Maher A, Marzang S, Hosseini SM. Correlation between Distribution of Hospital Inpatient Beds and Households expenditure in Iran. Health Based Research. 2016;2(3):275-87.

3. Liu W, Liu Y, Twum P, Li S. National equity of health resource allocation in China: data from 2009 to 2013. Int J Equity Health. 2016;15(1):68.

4. World Health Organization, Guidance on ethics and equitable access to HIV treatment and care. 2004.

5. Asante AD, Zwi AB. Factors influencing resource allocation decisions and equity in the health system of Ghana. Public Health 2009; 123(5):371-7.

6. Zhang Y, Wang Q, Jiang T, Wang J. Equity and efficiency of primary health care resource allocation in mainland China. Int J Equity Health. 2018;17(1):140.

7. Wenqi F, Liu G, Qunhong W, Hao M. Analysis of the variation trends of bed allocation and its equity at primary medical institutions in China. Int J Equity Health. 2016;32(3):217-20.

8. Hatam N, Zakeri M, Sadeghi A, Ramandi SD, Hayati R, Siavashi E. Equity analysis of hospital beds distribution in Shiraz, Iran 2014. Med J Islam Repub Iran. 2016;30:393.

9. Asl IM, Abolhallaje M, Raadabadi M, Nazari H, Nazari A, Salimi M, et al. Distribution of hospital beds in Tehran Province based on Gini coefficient and Lorenz curve from 2010 to 2012. Electron Physician. 2015;7(8):1653.

10. Meshkani Z, Moghaddam NM, Yekani NV, Nazari H, Moalemi S, Informatics. Inequality in the Distribution of Physicians in the South of Iran. J Health Manag Inform. 2018;5(3):96-103.

11. Aghamohamadi S, Jahangiri K, Hajinabi K, Masoudi A, Dehnavieh R. An insight study on the distribution of inpatient beds in hospitals: Iran, 2035. J Health Administ. 2018;21(71).

12. Meskarpour-Amiri M, Mehdizadeh P, Barouni M, Dopeykar N, Ramezanian M. Assessment the trend of inequality in the distribution of intensive care beds in Iran: using GINI index. Glob J Health Sci. 2014;6(6):28.

13. Anand S. Measuring Health Workforce Inequalities: Methods and Application to China and India. Human Resources for Health Observer, No. 5, 2010. Department of Human Resources for Health, World Health Organization Geneva; 2010.

14. Folland S, Goodman AC, Stano M. The economics of health and health care: Pearson Prentice Hall Upper Saddle River, NJ; 2007.

15. Brown MC. Using Gini-style indices to evaluate the spatial patterns of health practitioners: theoretical considerations and an application based on Alberta data. Soc Sci Med. 1994;38(9):1243-56.

16. Pilerudi S. Health Network of City. Tehran, Iran: Razavie Publication. 2006.

17. Mirsaeid G, Javad S, Mirzaie M, Haghshenas E, Dargahi H. Human resources distribution among Tehran university of Medical Sciences Hospitals. Payavard Salamat. 2014;7(5):432-46.

18. de Bruin AM, Bekker R, van Zanten L, Koole GM. Dimensioning hospital wards using the Erlang loss model. Ann Oper Res. 2010;178(1):23-43.

19. Horev T, Pesis-Katz I, Mukamel DB. Trends in geographic disparities in allocation of health care resources in the US. Health policy (Amsterdam, Netherlands). Health Policy. 2004;68(2):223-32.

20. Olsen ØE, Ndeki S, Norheim OF. Human resources for emergency obstetric care in northern Tanzania: distribution of quantity or quality? Hum Resour Health. 2005;3(1):5.

21. Matsumoto M, Inoue K, Farmer J, Inada H, Kajii E. Geographic distribution of primary care physicians in Japan and Britain. Health Place. 2010;16(1):164-6.

22. Calman K. The ethics of allocation of scarce health care resources: a view from the centre. J Med Ethics. 1994;20(2):71-4.

23. Asada Y. Assessment of the health of Americans: the average health-related quality of life and its inequality across individuals and groups. Popul Health Metr. 2005;3(1):7.

24. Lai D, Huang J, Risser JM, Kapadia AS. Statistical properties of generalized Gini coefficient with application to health inequality measurement. Soc Indic Res. 2008;87(2):249-58.

25. Grobler L, Marais BJ, Mabunda S, Marindi P, Reuter H, Volmink J. Interventions for increasing the proportion of health professionals practising in rural and other underserved areas. Cochrane Database Syst Rev. 2009;1(1).

26. Rabinowitz HK, Diamond JJ, Markham FW, Rabinowitz C. Longterm retention of graduates from a program to increase the supply of rural family physicians. Acad Med. 2005;80(8):728-32.

27. Pathman DE, Taylor Jr DH, Konrad TR, King TS, Harris T, Henderson TM, et al. State scholarship, loan forgiveness, and related programs: the unheralded safety net. JAMA. 2000;284(16):2084-92.

28. Pathman DE, Konrad TR, King TS, Taylor Jr DH, Koch GG. Outcomes of states' scholarship, loan repayment, and related programs for physicians. Med Care. 2004;42(6):560-8. 